\title{
KAJIAN PENGAWASAN APRON OLEH APRON MOVEMENT CONTROL (AMC) DALAM MENINGKATKAN KEDISIPLINAN DI APRON PT ANGKASA PURA I (PERSERO) BANDAR UDARA ADI SOEMARMO SURAKARTA TAHUN 2019
}

\author{
* Aswanti Setyawati ${ }^{1}$, Fransiskus Kresna Aristiyanto ${ }^{2}$ \\ ${ }^{1,2}$ Institut Transportasi dan Logistik Trisakti, Jakarta, Indonesia
}

*Email Korespondensi: murgiyanto@gmail.com

\section{ARTIKEL INFORMASI}

Diterima:

24 Juni 2021

Direvisi:

12 Juli 2021

Dipublikasi:

22 Juli 2021

\begin{abstract}
ABSTRAK
Adapun permasalahan dalam penelitian ini adalah bagaimana pengawasan Standart Operatinal Procedure oleh petugas unit AMC di Bandar Udara Adi Soemarmo Surakarta, bagaimana pelanggaran yang dilakukan pada sisi udara (airside) di Bandar Udara Adi Soemarmo Surakarta (data tahun 2019), bagaimana peran kerja unit AMC dalam menaikan tingkat kedisiplinan di apron Bandar Udara Adi Soemarmo Surakarta. Tujuan penelitian ini adalah untuk mengetahui pengawasan Standart Operational Procedure oleh petugas unit AMC di Bandar Udara Adi Soemarmo Surakarta untuk mengetahui pelanggaran yang dilakukan pada sisi udara (airside) di Bandar Udara Adi Soemarmo Surakarta, untuk mengetahui Peran kerja unit AMC dalam menaikan tingkat kedisiplinan di apron Bandar Udara Adi Soemarmo Surakarta. Metode penelitian yang digunakan ialah metode deskriptif dengan pendekatan kualitatif menggunakan analisis fishbone diagram, dalam teknik pengumpulan data menggunakan wawancara, observasi serta penyebaran kuisioner dan memanfaatkan data dokumen serta riset kepustakaan. Dari hasil analisis dan pembahasan menghasilkan perlu nya koordinasi antar stakeholders dalam menjalankan Standart Operational Procedure (SOP) pada pelayanan pemakaian garbarata, terdapat total 44 pelanggaran dari berbagai macam bentuk pelanggaran di area sisi udara (airside), aspek terendah pada peran kerja unit AMC dalam menaikan tingkat kedisiplinan yaitu manpower, manchines, dan dua subvariabel motivation.
\end{abstract}

Kata Kunci: Pengawasan Apron, Apron Movement Control (AMC), Kedisiplinan

\section{PENDAHULUAN}

Bandar Udara adalah kawasan di daratan dan/atau perairan dengan batas-batas tertentu yang digunakan sebagai tempat pesawat udara mendarat dan lepas landas, naik turun penumpang, bongkar muat barang dan tempat perpindahan intra dan antarmoda transportasi, yang dilengkapi dengan fasilitas keselamatan dan keamanan penerbangan, serta fasilitas pokok dan fasilitas penunjang lainnya. Bandar Udara menurut Annex ( 2004), disebutkan "Aerodrome, A defend area on land or water (including any building, installations, and equipment) intened to be used either wholly or in part for the arrival, departure and surface movement 
aircraft". "Aerodrome, merupakan area pertahanan di darat atau air (termasuk bangunan, instalasi, dan peralatan) berfungsi untuk digunakan baik seluruhnya atau sebagian untuk kedatangan, keberangkatan, dan pergerakan pesawat permukaan".

Sisi udara (airside) merupakan salah satu bagian paling vital dalam Bandar udara, airside atau sisi udara juga berhubungan dengan segala aktifitas take off (lepas landas) dan landing (pendaratan) terdapat tiga bagian pada sisi udara yaitu runway, taxiway dan apron, salah satu yang menjadi perhatian serius adalah bagian apron yang mana menjadi tempat parkir pesawat. Apron pada sisi udara (airside) diharuskan dalam keadaan sterile dari kegiatan yang membahayakan. Seperti yang diketahui pelanggaran pada bagian apron seperti memasuki wilayah sisi udara (airside) tidak sesuai pas bandara yang berlaku, tidak mengenakan alat pelindung diri (APD), mengendarakan kendaraan dengan tidak memiliki tanda izin mengemudi (TIM), tidak mempunyai pas bandara, mengenakan pas bandara orang lain hingga berkendara melebihi $25 \mathrm{~km} / \mathrm{jam}$ pada service road.

Tabel 1. Tabel Daftar Pelanggaran Pada Sisi Udara

\begin{tabular}{cll}
\hline No. & Jenis Pelanggaran & Kategori \\
\hline 1. & $\begin{array}{l}\text { Memasuki Wilayah sisi udara (airside) tidak sesuai dengan PAS } \\
\text { bandara. }\end{array}$ & Berat \\
\hline 2. & Tidak mengenakan alat pelindung diri (APD). & Berat \\
\hline 3. & Tidak memiliki tanda izin mengemudi (TIM). & Berat \\
\hline 4. & Tidak mempuyai PAS bandara. & Berat \\
\hline 5. & Mengenakan PAS orang lain. & Berat \\
\hline 6. & Berkendara melebihi 25km/jam pada service road. & Berat \\
\hline
\end{tabular}

Sumber : Apron Movement Control (AMC)

Bandar Udara Adi Soemarmo Surakarta merupakan salah satu Bandar udara sibuk di Indonesia melayani pelayanan penerbangan sipil domestik dan internasional di bawah pengelolaan PT Angkasa Pura I (Persero), menitikberatkan pelayanan pada kawasan Indonesia bagian tengah dan kawasan Indonesia bagian timur. PT Angkasa Pura I (Persero) mengatur dan mengoperasionalkan 13 Bandar Udara, 5 anak perusahaan serta 1 Strategic Business Unit. Oleh karena itu setiap organisasi yang bergerak dibidang pelayanan jasa Bandar Udara diharuskan untuk menjadikan kepuasan konsumen sebagai tujuan akhir. Di sisi lain dengan bertambah banyaknya jumlah pesawat terbang maka akan berimabas langsung pada mobilitas pergerakan di apron hal ini tentunya di perlukan pengawasan penuh terhadap kondisi, obyek, dan kegiatan serta pelayanan di apron yang dilaksanakan oleh Apron Movement Control (AMC) serta diharapkan dapat meningkatkan tingkat kedisiplinan petugas sisi udara (airside).

Pengawasan dilakukan terhadap semua pergerakan yang ada di apron seperti mengatur dan mengawasi parking stand pesawat, mengawasi aviobridge pada saat akan digunakan, mengawasi segala bentuk pergerakan kendaraan atau orang pada sisi udara, mengawasi kegiatan pengisian bahan bakar pesawat (refeuling), dan mengawasi kebersihan apron agar terhindar dari foreign object demage (FOD) yang dapat membahayakan keselamatan penerbangan baik take off maupun landing.

Dalam hal ini peneliti mengamati terdapat kurangnya pengawasan yang di lakukan oleh petugas unit kerja Apron Movement Control (AMC) terhadap pergerakan yang ada di apron sehingga ditemukan seperti memasuki wilayah sisi udara (airside) tidak sesuai pas bandara yang berlaku, tidak mengenakan alat pelindung diri (APD), mengendarakan kendaraan dengan tidak memiliki tanda izin mengemudi (TIM), tidak mempunyai pas bandara, mengenakan pas bandara orang lain hingga berkendara melebihi $25 \mathrm{~km} / \mathrm{jam}$ pada service road.

Sejalan dengan hal itu fungsi pengawasan merupakan hal penting di Bandar Udara lain seperti di jelaskan dalam Raihan Pamungkas, Aulia Regia SP, Bahri Ramadan (2019) Menyebutkan "pengawasan ketertiban di apron Terminal 3 Bandar Udara Internasional Soekarno - Hatta Jakarta yang dilakukan oleh personil AMC merupakan kegiatan yang sangat penting. Semakin bertambahnya jumlah penerbangan disertai dengan peralatan penunjang pelayanan darat pesawat udara (GSE) yang juga berpengaruh terhadap bertambahnya pergerakan di apron, maka semakin besar potensi pelanggaran ketertiban di apron. Melihat kondisi saat ini pergerakan kendaraan yang beroperasi di sisi udara semakin bertambah seiring dengan jumlah pesawat yang tinggal landas di Bandar Udara Internasional Soekarno-Hatta, maka sudah sewajarnya Personil Apron 
Movement Control (AMC) meningkatkan fungsi pengawasan guna mencegah terjadinya pelanggaran yang dapat mengancam keselamatan penerbangan di sisi udara.

Maka di perlukan penanganan yang baik untuk mewujudkan keamanan, keselamatan, kelancaran dan kemayamanan bagi jasa Bandar Udara. Fungsi pengawasan guna mencegah terjadinya pelanggaran yang dapat mengancam keselamatan penerbangan di sisi udara. Maka di perlukan penanganan yang baik untuk mewujudkan keamanan, keselamatan, kelancaran dan kemayamanan bagi jasa Bandar Udara. Fungsi pengawasan harus dilakukan secara optimal oleh unit Apron Movement Control (AMC) agar meningkatkan kedisiplinan petugas sisi udara (airside) dalam rangka mewujudkan fungsi tugas pemanduan, pengamanan, dan pengawasan dalam menciptakan keselamatan penerbangan, dengan meningkatkan tingkat kedisiplinan. Pengertian disiplin kerja menurut Edy Sutrisno (2016) menyebutkan bahwa "perilaku seseorang yang sesuai dengan peraturan, prosedur kerja yang ada atau disiplin adalah sikap, tingkah laku, dan perbuatan yang sesuai dengan peraturan dari organisasi baik tertulis maupun tidak tertulis.”

Sejalan dengan Undang-Undang No.1 Tahun 2009 tentang penerbangan dalam Pasal 312 ayat (3) tentang Pengawasan Penerbangan disebutkan "Pelaksanaan pengawasan sebagaimana dimaksud pada ayat (2) dilakukan oleh unit kerja atau lembaga penyelenggara pelayanan umum." Pengawasan yang maksimal di perlukan oleh unit kerja Apron Movement Control (AMC) dalam meningkatkan kedisiplinan petugas sisi udara (airside) diharapkan bisa meminimalisir terjadinya kecelakaan. fokus penelitian tersebut secara lebih spesifik dirinci menjadi sub-fokus sub-fokus sebagai berikut : 1)Pengawasan Standart Operational Proc edure (SOP) oleh petugas unit Apron Movement Control (AMC) di Bandar Udara Adi Soemarmo Surakarta tahun 2019, 2) Pelanggaran yang dilakukan pada sisi udara (airside) di Bandar Udara Adi Soemarmo Surakarta tahun 2019, 3) Peran kerja unit Apron Movement Control (AMC) dalam menaikan tingkat kedisiplinan di apron Bandar Udara Adi Soemarmo Surakarta. Tujuan Penelitian 1) Untuk mengetahui pengawasan Standart Operational Procedure (SOP) oleh petugas unit Apron Movement Control (AMC) di Bandar Udara Adi Soemarmo Surakarta tahun 2019, 2) Untuk mengetahui Pelanggaran yang dilakukan pada sisi udara (airside) di Bandar Udara Adi Soemarmo Surakarta tahun 2019. Tujuan penelitian ialah, 2) Untuk mengetahui Peran kerja unit Apron Movement Control (AMC) dalam menaikan tingkat kedisiplinan di apron Bandar Udara Adi Soemarmo Surakarta.

\section{KAJIAN PUSTAKA}

Pengertian manajemen sumber daya manusia, Manullang (2018) menyatakan bahwa manajemen adalah seni dan ilmu perencanaan, pengorganisasian, penyusunan, pengarahan dan pengawasan sumberdaya manusia untuk mencapai tujuan yang sudah ditetapkan terlebih dahulu. Pengertian manajemen sumber daya manusia, Widodo (2015) menyatakan bahwa suatu proses yang mencakup evaluasi terhadap kebutuhan SDM, mendapatkan orang-orang untuk memenuhi kebutuhan itu, dan mengoptimalisasikan pendayagunaan sumber daya yang penting tersebut dengan cara memberikan insentif dan penugasan yang tepat, agar sesuai dengan kebutuhan dan tujuan organisasi dimana SDM itu berada. Pengertian manajemen sumber daya manusia menurut Hasibuan (2016) menyatakan bahwa "ilmu dan seni mengatur hubungan dan peranan tenaga kerja agar efektif dan efesien membantu terwujudnya tujuan perusahaan, karyawan, dan masyarakat.

Pengertian manajemen sumber daya manusia menurut Sinambela (2017) menyatakan "pengelolaan sumber daya manusia sebagai sumber daya atau asset yang utama, melalui penerapan fungsi manajemen maupun fungsi operasional sehingga tujuan organisasi yang telah ditetapkan dapat tercapai dengan baik."

Dari uraian diatas dapat disimpulkan tentang pengertian manajemen sumberdaya manusia adalah "sebagai suatu proses mendayagunakan manusia sebagai tenaga kerja secara manusiawi dan mengoptimalisasikan pendayagunaan sumber daya yang penting tersebut dengan cara memberikan insentif dan penugasan yang tepat melalui penerapan fungsi manajemen maupun fungsi operasional sehingga tujuan organisasi yang telah ditetapkan dapat tercapai dengan baik."

Heizer dan Render (2015) menyatakan bahwa "manajemen operasi sebagai serangkaian aktivitas yang menghasilkan nilai dalam bentuk barang dan jasa dengan mengubah masukan menjadi hasil." Tampubolon (2014) menyatakan bahwa "dapat dinyatakan bahwa manajemen operasional bertanggung jawab untuk mengelola bagian atau fungsi di dalam organisasi yang meghasilkan barang dan jasa."

Render (2014) menyatakan bahwa "manajemen operasi (OM) adalah serangakaian kegiatan yang menciptakan nilai dalam bentuk barang dan jasa dengan mengubah input menjadi output." Dari uraian diatas dapat disimpulkan tentang pengertian manajemen operasional adalah "serangkaian aktivitas yang menghasilkan 
nilai dalam bentuk barang dan jasa dengan mengubah masukan menjadi hasil dan bertanggung jawab untuk mengelola bagian atau fungsi di dalam organisasi yang meghasilkan barang dan jasa."

Undang-Undang No.1 Tahun 2009 tentang penerbangan dalam pasal 1 ayat (33) Ketentuan Umum disebutkan "Bandar Udara adalah kasawan di daratan dan/atau perairan dengan batas-batas tertentu yang digunakan sebagai tempat pesawat udara mendarat dan lepas landas, naik turun penumpang, bongkar muat barang, dan tempat perpindahan barang intra dan antar moda transportasi, yang dilengkapi dengan fasilitas keselamatan dan keamanan penerbangan, serta fasilitas pokok dan fasilitas penunjang lainnya."

Bandar Udara menurut Annex (2004) "Aerodrome, A defend area on land or water (including any building, installations, and equipment) intened to be used either wholly or in part for the arrival, departure and surface movement aircraft". "Aerodrome, merupakan area pertahanan di darat atau air (termasuk bangunan, instalasi, dan peralatan) berfungsi untuk digunakan baik seluruhnya atau sebagian untuk kedatangan, keberangkatan, dan pergerakan pesawat di permukaan".

Di jelaskan dalam Annex (2004) "Apron is defined Area, on a land aerodrome, intended to accommodate aircraft for purposes of loading, or unloading passenger, mail or cargo, fuelling, parking or maintenance." apron adalah "suatu area tertentu di daratan Aerodrome yang dimaksudkan untuk menampung pesawat dengan tujuan bongkar muat penumpang, pos atau kargo, pengisian bahan bakar, parkir atau pemeliharaan pesawat." Fungsi tugas unit Apron Movement Control (AMC) adalah unit kerja sesuai yang diatur dalam Standart Operasional Apron Movement Control Version 1.0 PT Angkasa Pura 1 (Persero) mempunyai fungsi melakukan pengawasan penuh terhadap kondisi, obyek, dan kegiatan serta pelayanan di apron. Untuk dapat terwujudnya pelaksanaan tugas dan fungsi tersebut, maka harus didukung oleh fasilitas / peralatan yang baik dan selalu siap operasi, personel yang terampil dan selalu siap tugas, serta standar pelayanan sesuai dengan ketentuan . Unit kerja Apron Movement Control (AMC) di Kantor Cabang PT Angkasa Pura 1 (Persero) adalah unit pelaksana struktural di lingkungan perusahaan yang berada di bawah divisi Airport Operation, Service \& Hospitality. Sesuai dengan Standart Operasional Apron Movement Control Version 1.0 PT Angkasa Pura 1 (Persero) di jelaskan fungsi utama unit kerja Apron Movement Control (AMC) melakukan pengawasan penuh terhadap kondisi, obyek, dan kegiatan serta pelayanan di apron. Namun saat ini fungsi pengawasan dirasa belum berjalan secara optimal, kedepan fungsi pengawasan yang baik harus ditingkatkan dan diharapkan mampu meningkatkan tingkat kedisiplinan di daerah sisi udara (airside) Bandar Udara. Fungsi pengawasan yang dilakukan oleh unit kerja Apron Movement Control (AMC) diperkuat dalam Undang-Undang No.1 Tahun 2009 tentang penerbangan dalam Pasal 312 tentang Pengawasan Penerbangan.

Dalam meningkatkan tigkat kedisiplinan diperlukan suatu standar operasional prosedur (SOP) dalam kegiatan kerja Apron Movement Control (AMC) sebagai pedoman dalam pelaksanaan kegiatan operasional di wilayah apron bandar udara seperti diatur dalam Standart Operasional Apron Movement Control Version 1.0 PT Angkasa Pura 1 (Persero). Diharapkan kepada semua unsur/unit kerja terkait dapat melaksanakan tugas dan kewenangan dengan penuh rasa tanggung jawab. Berikut ini adalah rangkuman Standard Operating Procedure (SOP) atau Prosedur Mutu / Instruksi Kerja yang harus disiapkan oleh unit Apron Movement Control dalam melaksanakan pekerjaan.

a. Manajemen Keselamatan Apron :

1) Prosedur pengawasan area berbahaya.

2) Prosedur pengawasan perlindungan terhadap engine jet-blast / intake.

3) Prosedur pengawasan engine run-up.

4) Prosedur push-back \& start engine pesawat udara.

5) Prosedur pengawasan kegiatan push-back \& start engine pesawat udara.

6) Prosedur pengawasan pencegahan bahaya kebakaran.

7) Prosedur pengawasan keselamatan saat pengisian bahan bakar pesawat udara.

8) Prosedur pengawasan kebersihan apron.

9) Prosedur pengawasan dan penanganan Foreign Object Damage (FOD).

10) Prosedur penanganan tumpahan bahan bakar / bahan pelumas.

b. Manajemen Pengoperasian Apron :

1) Prosedur komunikasi.

2) Prosedur pengawasan passenger handling dan baggage handling.

3) Prosedur plotting parkir pesawat udara.

4) Prosedur penggunaan parkir pesawat temporary (sementara). 
5) Prosedur penempatan parkir pesawat udara di luar kondisi normal (unusual parking conditions).

6) Prosedur Reposisi Parkir Pesawat Udara.

7) Prosedur pengoperasian garbarata/aviobridge.

8) Prosedur pengawasan pelayanan garbarata/aviobridge.

9) Prosedur pengawasan ground support equipment (GSE).

10) Prosedur pemanduan parkir pesawat udara (marshalling service).

11) Prosedur pemanduan parkir pesawat udara menggunakan Visual Docking Guidance System / Automatic Docking Guidance System (VDGS/ADGS.)

12) Prosedur pengawasan kelengkapan pemasangan wheel-chock dan safety cones pada pesawat udara.

13) Prosedur operasi dalam cuaca buruk.

14) Prosedur pengawasan kendaraan di wilayah airside.

15) Prosedur pengoperasian/pelayanan follow-me car.

16) Prosedur penerbitan Tanda Izin Mengemudi (TIM).

Dalam kesehariannya ditemui banyaknya pelanggaran yang terjadi di apron dikarenakan kurangnya pemahaman akan pentingnya ketertiban di sisi udara (airside). Tentu hal tersebut tidak sejalan dengan prinsip penerbangan yang mengutamakan zero accident yang menciptakan safety and security.

\section{Pelanggaran Sisi Udara (Aiside)}

1. Pelanggaran menurut Kamus Besar Bahasa Indonesia (KBBI) adalah perbuatan (perkara) melanggar.

2. Pelanggaran sisi udara (airside) adalah suatu tindakan oleh suatu organisasi (badan usaha) atau personel yang tidak sesuai dengan aturan yang berlaku di dalam Bandar Udara.

Untuk lebih jelasnya maka penulis mengelompokan beberapa pelanggaran dan sanksi yang terjadi di area sisi udara (airside) pada bagian apron yaitu pada table 2.1

Tabel 2. Daftar Pelanggaran Pada Sisi Udara (Airside)

\begin{tabular}{llll}
\hline No & Jenis Pelanggaran & Kategori & Sanksi Administrasi \\
\hline 1 & $\begin{array}{l}\text { Memasuki wilayah sisi udara (airside) tidak sesuai } \\
\text { dengan PAS bandara. }\end{array}$ & Berat & Segera meninggalkan sisi udara. \\
\hline 2 & Tidak mengenakan alat pelindung diri (APD). & Berat & PAS Bandara di tahan 14 Hari. \\
\hline 3 & Tidak memiliki tanda izin mengemudi (TIM). & Berat & PAS Bandara di tahan 14 Hari. \\
\hline 4 & Tidak mempuyai PAS bandara. & Berat & Segera meninggalkan sisi udara. \\
\hline 5 & Mengenakan PAS orang lain. & Berat & Segera meninggalkan sisi udara. \\
\hline 6 & Berkendara melebihi 25km/jam pada service road. & Berat & PAS Bandara di tahan 14 Hari. \\
\hline & Sumber: Apron Movement Control (AMC). & &
\end{tabular}

Dijelaskan dalam Airside Safety Manual version 1.0 PT Angkasa Pura I (Persero) petugas ramp handling atau koordinator ramp handling adalah "personil yang bertanggung jawab dalam pelaksanaan pemberian pelayanan kepada pesawat udara selama berada di darat, sejak kedatangan sampai dengan keberangkatan pesawat udara."

\section{Penggunaan Aviobridge / Garbarata}

Gambar1. No Parking Area \& Equipment Parking Area

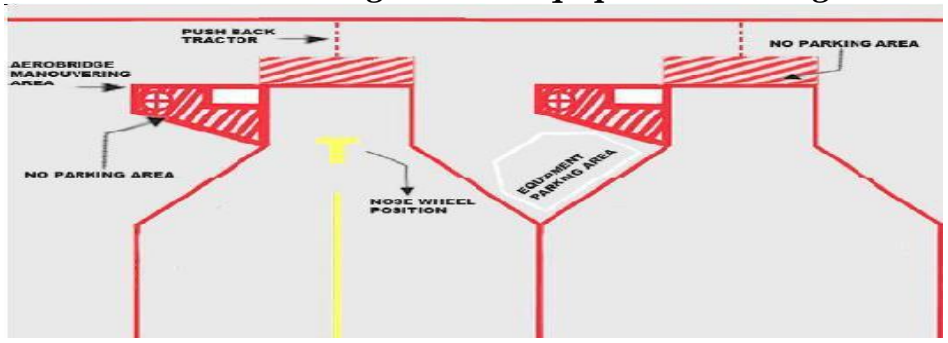

Sumber: Pedoman Pengoprasian Kendaraan di Airside Version1.0 PT Angkasa Pura I 
Dijelaskan dalam Airside Safety Manual version 1.0 PT Angkasa Pura I (Persero) garbarata (aviobrige) adalah "fasilitas berupa lorong yang menghubungkan pesawat udara dengan gedung terminal bandar udara yang dipergunakan untuk naik turun penumpang ke dan dari pesawat udara atau ke dan dari gedung terminal bandar udara." Pada saat pengoprasian nya semua kendaraan atau peralatan dilarang parkir atau lewat di bawah garbarata dan harus segera menyingkir dari daerah lintasan ketika garbarata tersebut dioperasikan dan juga dilarang menaikkan atau menurunkan penumpang melalui service stairs atau tangga besi di sisi garbarata. Pada keseharian operasionalnya airline operator/ground handling harus mengikuti aturan pemaikaian garbarata seperti :

1. Airline operator/ground handling operator harus menjaga kebersihan aviobridge/garbarata.

2. Airline operator/ground handling operator harus membersihkan sampah/kotoran yang disebabkan oleh petugas dan atau penumpang dari pesawat udara yang dilayani.

3. Airline operator/ground handling operator dilarang untuk menyentuh peralatan dan atau tombol yang terdapat di garbarata.

4. Airline operator/ground handling operator harus mengawasi dan melarang penumpang untuk menyentuh peralatan dan atau tombol yang terdapat di garbarata.

5. Airline operator/ground handling operator agar menginformasikan kepada petugas apron movement control (AMC) apabila terjadi gangguan, bunyi alarm, atau hal lainnya yang dirasa dapat menimbulkan bahaya.

Dijelaskan dalam Airside Safety Manual version 1.0 PT Angkasa Pura I (Persero) peralatan pelayanan darat pesawat udara (Ground Support Equipment/GSE) adalah alat - alat bantu yang dipersiapkan untuk keperluan pesawat udara di darat pada saat kedatangan atau keberangkatan, pemuatan dan atau penurunan penumpang, kargo dan pos. Dalam pelaksanaannya Airline operator/ground handling operator harus mematuhi standar persyaratan teknis maupun operasional seperti :

1. Airline operator/ground handling operator harus mematuhi standar persyaratan teknis maupun operasional yang ditentukan oleh Keputusan Direktur Jenderal Perhubungan Udara Nomor : KP 635 Tahun 2015 tentang standar peralatan penunjang pelayanan darat pesawat udara (ground support equipment/GSE) dan kendaraan operasional yang beroperasi di sisi udara.

2. Airline operator/ground handling operator harus mematuhi pembatasan usia peralatan yang ditentukan oleh Peraturan Menteri Perhubungan Nomor : PM 174 Tahun 2015 tentang pembatasan usia peralatan penunjang pelayanan darat pesawat udara (ground support equipment/GSE) dan kendaraan operasional yang beroperasi di sisi udara.

3. Kendaraan selain GSE yang sedang / akan memberikan pelayanan kepada pesawat tidak diperbolehkan masuk ke dalam apron, kecuali terdapat izin dari apron movement control.

4. Peralatan maupun kendaraan GSE harus dioperasikan oleh petugas yang memiliki kompetensi yang sesuai dan masih berlaku.

5. Peralatan atau kendaraan GSE harus dalam kondisi baik dan telah memiliki sertifikasi.

6. Segala bentuk perubahan bentuk dan fungsi dari peralatan maupun kendaraan harus dilakukan sertifikasi ulang dan dilaporkan kepada pihak pengelola bandara.

7. Kendaraan atau peralatan GSE yang mengalami kerusakan dan telah diperbaiki apabila hendak dipergunakan kembali harus dilaporkan kepada pihak pengelola bandara untuk dilakukan pemeriksaan.

8. Penempatan posisi peralatan atau kendaraan GSE pada waktu melayani pesawat udara agar diatur sesuai dengan ketentuan teknis pesawat udara yang bersangkutan.

9. Peralatan yang sedang tidak digunakan agar diatur secara tertib dan dalam posisi di rem pada tempat yang telah disediakan.

10. Dilarang meninggalkan kendaraan di apron dalam keadaan mesin hidup.

11. Dilarang memindahkan peralatan melintasi apron melalui bagian belakang pesawat yang sedang parkir tanpa persetujuan dari unit AMC.

12. Mematuhi prosedur pengoperasian kendaraan sesuai dengan dokumen Pedoman pengoperasian kendaraan di wilayah airside version 1.0. yang dikeluarkan oleh pengelola bandara.

Pengertian disiplin menurut Hasibuan (2016, p.193) menyebutkan bahwa "adalah kesadaran dan kesidiaan seseorang yang menaati semua peraturan perusahaan dan norma-norma sosial yang berlaku." 
Pengertian disiplin menurut Muchdarsyah (2014, p. 135) menyebutkan bahwa "adalah sikap kejiwaan dari seseorang atau kelompok orang yang senantiasa berkehendak untuk mengikuti/mematuhi segala aturan/keputusan yang telah ditetapkan." Pengertian disiplin kerja menurut Edy Sutrisno (2016, p. 89) menyebutkan bahwa "prilaku seseorang yang sesuai dengan peraturan, prosedur kerja yang ada atau disiplin adalah sikap, tingkah laku, dan perbuatan yang sesuai dengan peraturan dari organisasi baik tertulis maupun tidak tertulis." Dari uraian diatas dapat disimpulkan tentang pengertian kedisipilinan adalah "adalah kesadaran dan kesidiaan seseorang yang menaati semua peraturan dan berkehendak untuk mengikuti/mematuhi segala keputusan, disiplin disini tidak diartikan sebagai hukuman untuk orang yang bersalah, tetapi merupakan didikan atau tuntutan untuk bermotivasi, bersikap, dan berkinerja baik secara konsisten."

Menurut Vincent Gaspersz (2012, p. 615) menyatakan bahwa "diagram sebab akibat (cause-effect diagram) adalah salah satu diagram yang menunjukan hubungan antara sebab dan akibat. Berkaitan dengan pengendalian proses statical, diagram sebab akibat dipergunakan untuk menunjukan faktor-faktor penyebab (sebab) dan karakteristik kualitas (akibat) yang disebabkan oleh faktor-faktor penyebab itu." Diagram sebab akibat (cause-effect diagram) seringkali disebut diagram "tulang ikan" (fishbone diagram) sebab bentuknya menyerupai kerangka tulang ikan. Diagram ini juga sering disebut diagram Ishikawa karena pertamakali diperkenalkan oleh Professor Kaouru Ishikawa dari Universtitas Tokyo pada tahun 1953. Inti dar diagram ini adalah dapat dipergunakan untuk kebutuhan-kebutuhan sebagai berikut :

1. Membantu mengidentifikasikan akar penyebab dari suatu masalah.

2. Membantu membangkitkan ide-ide untuk solusi suatu masalah.

3. Membantu dalam penyelidikan dan pencarian fakta lebih lanjut.

Langkah dalam pembuatan diagaram ini dapat dikemukakan sebgai berikut :

a. Mulai dengan pernyataan masalah-masalah utama penting dan mendesak untuk diselseaikan.

b. Tulislah pernyataan masalah itu pada "kepala ikan" yang merupakan akibat (effect).

c. Tuliskan faktor-faktor penyebab utama (sebab-sebab) yang mempengaruhi penyebab utama (tulang-tulang besar).

d. Tuliskan penyebab-penyebab sekunder yang mempengaruhi penyebab utama (tulang-tulang besar), serta penyebab-penyebab sekunder itu dinyatakan sebagai "tulang-tulang" berukuran sedang.

e. Tuliskan penyebab-penyebab tersier yang mempengaruhi penyebab-penyebab sekunder (tulang-tulang berukuran sedang) serta penyebab-penyebab tersier itu dinyatakan tulang tulang berukuran kecil.

f. Tentukan item-item yang penting dari setiap faktor dan tandailah faktor-faktor penting tertentu yang kelihatannya memiliki pengaruh nyata terhadap karakteristik kualitas.

g. Catatlah informasi yang perlu didalam diagram sebab akibat, misalnya : judul, nama produk, proses, kelompok, dll.

\section{Gambar 2. Bentuk Diagram Sebab-Akibat}

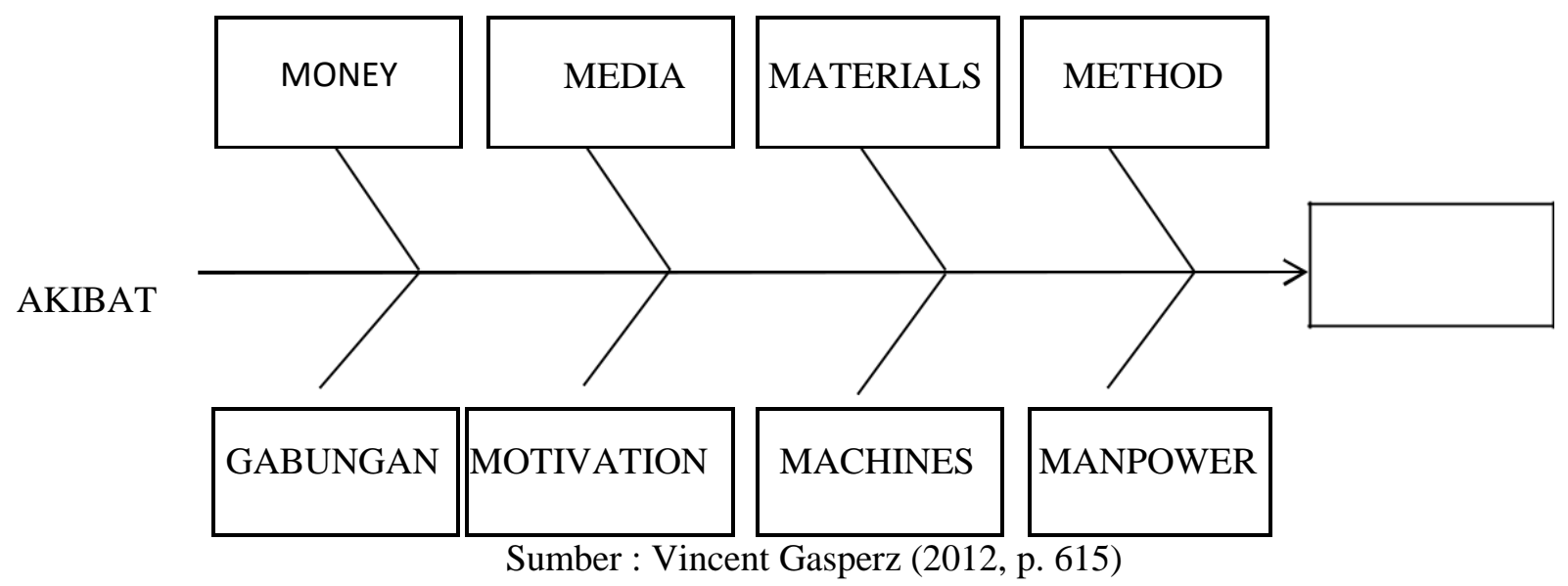

\section{METODE}


Metode yang digunakan dalam penelitian ini adalah metode deskriptif dengan pendekatan kualitatif, Penelitian ini dilakukan dalam dua tahap yaitu mengkaji hasil penelitian pendahulu, setelah itu melakukan penyebaran kuisioner dan obervasi lanjutan. Jenis data yang digunakan adalah kualitatif dan kuantitatif. Peneliti menggunakan analisis data dengan Fishbone Diagram.

\section{HASIL DAN PEMBAHASAN}

Peneliti melakukan wawancara dengan bagian Apron Movement Control (AMC ) sebagai informan, yaitu Bapak Rewanghadi Widagdo dalam kaitannya dengan analisis pengawasan apron oleh apron movement movement control (AMC) dalam meningkatkan kedisiplinan di apron,informan menyatakan bahwa "hambatan terbesar unit Apron Movement Control (AMC) adalah visualisasi terbatas dalam melakukan pengawasan di bagian sisi udara (airside), kita harus mempuyai kepanjangan tangan dari visualisasi kita yaitu CCTV yang saat ini belum bisa di terapkan dari semua parking stand bandara solo, saat ini visualisasi kita hanya bisa menjangkau 10 parking stand dari 15 parking stand yang ada karena terbatasnya visualisasi kita, lalu kurangnya kepekaan dari teman-teman AMC dalam melihat potensi-potensi yang timbul dari kebiasaankebiasaan teman teman ground handling yang dapat menyebabkan potensi pelanggaran atau potensi hazard yang dapat menyebabkan accident incindent di sisi udara tersebut yang di pastikan menyebabkan fungsi pengawasan yang di lakukan AMC belum maksimal dalam meningkatkan kedisipilinan."

Informan menjelaskan bahwa hambatan terbersar yang di miliki oleh unit Apron Movement Control (AMC) dalam melakukan pengawasan adalah terbatasnya jarak pandang atau visualisasi personil Apron Movement Control (AMC) itu sendiri dalam melakukan pengawasan di sisi udara, informan menilai saat ini di perlukan kepanjangan tangan dari visualisasi itu sendiri yaitu CCTV yang saat ini belum bisa di terapkan di semua parking stand yang ada, ketika bertugas visualisasi unit Apron Movement Control (AMC) hanya bisa menjangkau 10 parking stand dari 15 parking stand yang ada karena terbatasnya kemampuan jarak pandang petugas, selain itu informan menilai terdapat kurangnya kepekaan dari unit Apron Movement Control (AMC) itu sendiri dalam melihat potensi-potensi yang timbul dari kebiasaan petugas sisi udara (airside) yang dapat menyebabkan potensi pelanggaran atau potensi hazard yang kapan saja dapat menyebabkan accident dan incident, informan juga memberikan kesimpulan pengawasan yang dilakukan oleh unit Apron Movement Control (AMC) belum maksimal karena adanya faktor internal dan external itu sendiri yang menghambat dalam pengawasan.

Peneliti melakukan wawancara dengan bagian petugas sisi udara (airside) sebagai informan, yaitu Bapak Muhamad Noor sebagai Team Leader Operation dan Flight Dispatcher PT Gapura Angkasa cabang Bandar Udara Adi Soemarmo Surakarta dalam kaitannya dengan analisis pengawasan apron oleh apron movement movement control (AMC) dalam meningkatkan kedisiplinan di apron,informan menyatakan bahwa :

"pada dasarnya pengawasan AMC di Bandara Adi Soemarmo ini sudah bagus dan cukup detail seperti peletakan peralatan yang bukan pada tempatnya pun kita di tegur, menurut saya dalam keseharian nya koordinasi antar petugas airside dan AMC sudah berjalan, pada keseharianya apabila petugas airside melakukan pelanggaran ditindak sesuai dengan ketentuan yang berlaku tapi terdapat perbedaan antara petugas AMC, beda petugas beda treatment yang diberikan walaupun tujuannya sama, terkadang petugas sisi udara terpaksa melakukan pelanggaran karena beban kerja berat yang di miliki dan harus segera bekerja sehingga terkadang pelanggaran itu terjadi, contoh seperti dalam melakukan pelayanan sisi udara dan lupa membawa PAS bandara sehingga meminjam PAS bandara orang lain karena apabila harus kembali ke rumah dan mengambil PAS bandara akan menyebabkan take time, pengkajian ulang harus di lakukan oleh AMC ketika menemukan pelanggaran seperti itu melihat runtutan masalah di balik suatu pelanggaran yang terjadi, harapan kedepan komunikasi selalu intens antara AMC dengan petugas sisi udara jangan sampai ada perasaan like and dislike dalam menjalankan operasional keseharian karena terkadang tiap personal juga ada yang menampilkan persaan seperti itu, karena tiap personal kan pribadi nya beda-beda."

Informan menjelaskan bahwa pada dasarnya pengawasan yang dilakukan oleh unit Apron Movement Control (AMC) di Bandar Udara Adi Soemarmo Surakarta sudah baik dan cukup detail pada beberapa hal seperti peletakan peralatan yang pada bukan tempatnya akan mendapat teguran, informan pun menilai koordinasi antar petugas sisi udara (airside) dengan petugas Apron Movement Control (AMC) sudah berjalan baik, pada sisi penindakan yang di lakukan oleh unit Apron Movement Control (AMC) informan beranggapan sudah dilakukan dengan baik dan tidak subyektif walaupun terdapat perbedaan treatment yang diberikan oleh tiap petugas Apron Movement Control (AMC) ketika menindak petugas sisi udara (airside) jika terdapat pelanggaran walaupun maksud dan tujuan nya sama, informan menjelaskan terdapat adanya beban kerja yang 
berat di tanggung oleh petugas sisi udara (airside) dalam menjalankan tugas keseharian nya dan itu pun yang terkadang menjadikan timbulnya sebuah pelanggaran yang terjadi, ini pula yang di harapkan oleh informan untuk menjadi kajian bersama dengan unit Apron Movement Control (AMC) apabila menemukan pelanggaran seperti itu untuk melihat runtutan masalah yang terjadi yang mendorong terjadinya sebuah pelanggaran, harapan kedepan komunikasi selalu intens antara petugas sisi udara (airside) dan unit Apron Movement Control (AMC) agar tidak ada perasaan like and dislike dalam menjalankan operasional kesehariannya, karena informan menilai tiap personal yang mempunyai karakteristik berbeda-beda ada yang menampilakan perasaan like and dislike antara unit Apron Movement Control (AMC) dengan petugas sisi udara (airide) maka dari itu komunikasi harus lebih di tingkatkan kedepan untuk mengindari hal tersebut.

Setelah mendapatkan keterangan dari kedua informan penulis mewawancarai narasumber terkait yaitu Bapak Kasnoto sebagai Airport Duty Manager (ADM) Bandar Udara Adi Soemarmo Surakarta untuk melakukan triangulsi sumber berkaitan dengan penelitian penulis yaitu analisis pengawasan apron oleh apron movement control (AMC) dalam meningkatkan kedisplinan di apron, narasumber mengatakan : "pertama-tama di jelaskan tugas utama ADM adalah sebagai koordinator pengawas dalam operasional keseharian, tugas dan tanggung jawab ADM di bawah naungan general manager dan senior manager, menanggapi persoalan pengawasan apron oleh AMC dalam meningkatkan kedisiplinan di apron, pertama-tama koordinasi antara ADM selama ini dengan AMC sudah cukup baik dalam hal berkaitan dengan pengawasan di sisi udara walaupun belum sempurna, lalu pengawasan yang dilakukan oleh AMC dalam meningkatkan kedisiplinan sebenarnya belum bisa di katakan baik seutuhnya ditambah jumlah penerbangan yang masih bisa di handle serta masih dalam batas wajar, tapi kedepan apabila bandara adi soemarmo terdapat peningkatan penerbangan rasa nya petugas AMC harus mendaptkan pelatihan lebih baik lagi dan lebih ketat lagi dalam melakukan fungsi pengawasan daripada sekarang, nah terkait pelanggaran yang sudah terjadi di sisi udara sebenarnya selain pengawasan yang belum sempurna oleh AMC pihak airlines pun atau groundhandling sudah mempunyai SOP nya sendiri dalam menjalankan tugas dan ini harus bersinergritas antara AMC dengan pihak stakeholders petugas sisi udara, peningkatan sinergritas rasanya harus di lakukan dengan melakukan briefing bulanan antara AMC dengan stakeholders terkait yaitu petugas sisi udara perlu juga dihadirkan pihak safety dalam briefing bulanan itu untuk mengedukasi keselamatan dan keamanan penerbangan guna meminimalisir potensi terjadinya pelanggaran yang selama ini belum di laksanakan, saat ini pengembangan sistem juga sedang di laksanakan dengan penyempuranaan bagian airport operation control center (AOCC) ini juga merupakan langkah pemantauan operasional sisi udara."

Narasumber menjelaskan tugas utama Airport Duty Manager (ADM) adalah sebagai koordinator pengawas dalam operasional keseharian, dalam hal ini tugas dan tanggung jawab ADM ada di bawah manager dan senior manager, dalam hal pengawasan apron oleh Apron Movement Control (AMC) dalam meningkatkan kedisipilinan di apron narasumber menilai koordinasi antara Airport Duty Manager (ADM) dengan Apron Movement Control (AMC) pengawasan apron oleh apron movement control (AMC) dalam meningkatkan kedisplinan di apron, narasumber mengatakan : "pertama-tama di jelaskan tugas utama ADM adalah sebagai koordinator pengawas dalam operasional keseharian, tugas dan tanggung jawab ADM di bawah naungan general manager dan senior manager, menanggapi persoalan pengawasan apron oleh AMC dalam meningkatkan kedisiplinan di apron, pertama-tama koordinasi antara ADM selama ini dengan AMC sudah cukup baik dalam hal berkaitan dengan pengawasan di sisi udara walaupun belum sempurna, lalu pengawasan yang dilakukan oleh AMC dalam meningkatkan kedisiplinan sebenarnya belum bisa di katakan baik seutuhnya ditambah jumlah penerbangan yang masih bisa di handle serta masih dalam batas wajar, tapi kedepan apabila bandara adi soemarmo terdapat peningkatan penerbangan rasa nya petugas AMC harus mendaptkan pelatihan lebih baik lagi dan lebih ketat lagi dalam melakukan fungsi pengawasan daripada sekarang, nah terkait pelanggaran yang sudah terjadi di sisi udara sebenarnya selain pengawasan yang belum sempurna oleh AMC pihak airlines pun atau groundhandling sudah mempunyai SOP nya sendiri dalam menjalankan tugas dan ini harus bersinergritas antara AMC dengan pihak stakeholders petugas sisi udara, peningkatan sinergritas rasanya harus di lakukan dengan melakukan briefing bulanan antara AMC dengan stakeholders terkait yaitu petugas sisi udara perlu juga dihadirkan pihak safety dalam briefing bulanan itu untuk mengedukasi keselamatan dan keamanan penerbangan guna meminimalisir potensi terjadinya pelanggaran yang selama ini belum di laksanakan, saat ini pengembangan sistem juga sedang di laksanakan dengan penyempuranaan bagian airport operation control center (AOCC) ini juga merupakan langkah pemantauan operasional sisi udara."

Narasumber menjelaskan tugas utama Airport Duty Manager (ADM) adalah sebagai koordinator pengawas dalam operasional keseharian, dalam hal ini tugas dan tanggung jawab ADM ada di bawah manager dan senior manager, dalam hal pengawasan apron oleh Apron Movement Control (AMC) dalam meningkatkan 
kedisipilinan di apron narasumber menilai koordinasi antara Airport Duty Manager (ADM) dengan Apron Movement Control (AMC) Pengawasan Standar Operasional Prosedur (SOP) dan Pemakaian Jumlah Aviobridge/Garbarata Bandar Udara Adi Soemarmo Surakarta Tahun 2019.

Berdasarkan analisis hitungan grafik pada hasil penelitian maka pada tahun 2019 pemakaian aviobridge/garbarata memiliki jumlah 10109, yang dirata-ratakan menjadi 842,42 pemakaian aviobridge/garbarata dalam satu bulan, jumlah pemakaian aviobridge/garbarata tertinggi pada bulan Januari yaitu 970 kali pemakaian aviobridge/garbarata sedangkan pemakaian terendah terjadi pada bulan Mei yaitu 767 pemakaian aviobridge/garbarata, perhitungan ini juga memiliki rata-rata kegunaan baik pada saat kenaikan maupun pada saat penurunan sebesar -166 setiap bulan atau dapat diartikan rata-rata terjadi penurunan pemakaiam -1,64\% perbulan,penulis melihat pemakaian aviobridge/garbarata sangat di pengaruhi oleh hari raya nasional dan selesainya hari libur nasional pada tahun 2019 yang berpengaruh langsung pada tingkat penerbangan baik itu kedatangan maupun keberangkatan yang menggunakan parking stand 4, 6 dan 8 yang merupakan parking stand dilengkapi aviobridge/garbarata.

Pelanggaran yang dilakukan pada sisi udara (airside) di Bandar Udara Adi Soemarmo Surakarta tahun 2019. Dengan beragam nya jenis pelanggaran yang terjadi pada sisi udara (airside) diperlukan pengawasan yang lebih ketat lagi serta penanganan dan pemberian sanksi yang sesuai dengan pelanggaran yang di buat, pada tahun 2019 setidaknya terjadi 44 pelanggaran yang tercatat oleh unit apron movement control (AMC) dari 6 tipe generalisasi masalah seperti yang di jabarkan pada tabel berikut :

Tabel 3 Tabel Jumlah Akumulasi Pelanggaran

\begin{tabular}{ll}
\hline Memasuki wilayah sisi udara (airside) tidak sesuai dengan PAS Bandara & 10 Orang \\
\hline Tidak mengenakan alat pelindung diri (APD) & 7 Orang \\
\hline Tidak memiliki tanda izin mengemudi (TIM) & 6 Orang \\
\hline Tidak mempunyai PAS Bandara & 5 Orang \\
\hline Mengenakan PAS orang lain & 5 Orang \\
\hline Berkendara melebihi 25km/jam pada service road. & 11 Orang \\
\hline Jumlah & 44 Orang \\
\hline
\end{tabular}

Sumber : Data diolah peneliti

Pelanggaran yang paling sering di lakukan ialah berkendara melebihi $25 \mathrm{~km} / \mathrm{jam}$ pada service road dengan 11 orang yang melanggar tentu ini menjadi perhatian serius bagi unit apron movement control (AMC) untuk lebih meningkatkan pengawasan pada sisi udara demi menekan potensi-potensi pelanggaran yang mungkin saja dapat terjadi serta pelanggaran terendah pada tidak mempunyai PAS Bandara dan mengenakan PAS Bandara orang lain dengan 5 Orang yang melanggar, kendati menjadi pelanggaran dengan tingkat pelanggaran yang terendah namun penulis menemukan fakta bahwa pelnggaran tidak mempunyai PAS Bandara selalu diikuti dengan pelanggaran mengenakan PAS Bandara orang lain, apapun alasan yang mendasari hal itu tentu setiap pelanggaran harus menjadi perhatian serius dan harus di tindak sesuai dengan ketentuan yang berlaku.

Peran kerja unit Apron Movement Control (AMC) dalam menaikan tingkat kedisiplinan di apron Bandar Udara Adi Soemarmo Surakarta Tahun 2019. Peneliti dalam hal ini melakukan survey yang hasilnya telah dijabarkan dalam hasil penelitian dengan menggunakan metode kuisioner menggunakan skala likert 4 skala yang di sebarkan kepada karyawan PT Angkasa Pura I (Persero) Bandar Udara Adi Soemarmo Surakarta pada sub unit kerja Apron Movement Control (AMC), untuk mengetahui tanggapan mereka mengenai peran kerja unit Apron Movement Control (AMC) dalam menaikan tingkat kedisiplinan di apron Bandar Udara Adi Soemarmo Surakarta Tahun 2019, penulis memberikan 26 variabel pertanyaan menggunakan metode 7M Vincent Gasperz (2002, p. 106) dari 26 variabel penelitian terdapat 4 variabel dengan penilaian paling rendah yang mendekati $<50$ yang menjadi batas interval skala likert 4 skala suatu penilaian dapat dikatakan baik-baik saja, yang akan dijabarkan pada tabel berikut : 
Tabel 4 Tabel Hasil Terendah Variabel Penelitian

\begin{tabular}{lc}
\hline $\begin{array}{l}\text { (Man Power) } \\
\text { Petugas sisi udara selalu kooperatif dengan unit kerja AMC yang melakukan } \\
\text { pengawasan segala aktifitas sisi udara. }\end{array}$ & $66,6 \%$ \\
\hline $\begin{array}{l}\text { (Manchines) } \\
\text { Sarana penunjang kerja unit AMC seperti fasilitas penyimpanan dokumen dan } \\
\text { peralatan alat tulis kantor sudah tersedia dengan lengkap. }\end{array}$ & $66,6 \%$ \\
\hline $\begin{array}{l}\text { (Motivation) } \\
\text { Unit kerja AMC telah menerima pemberian penghargaan ketika berprestasi. }\end{array}$ & $52,7 \%$ \\
\hline $\begin{array}{l}\text { (Motivation) } \\
\text { Unit kerja AMC mempunyai motivasi kerja yang baik karena apresiasi diberikan oleh } \\
\text { pimpinan ketika unit AMC mencapai kinerja yang diharapkan. }\end{array}$ & $55,5 \%$ \\
\hline
\end{tabular}

Sumber : Data diolah peneliti

Penulis melihat perlunya perbaikan komunikasi antar unit apron movement control (AMC) dengan seluruh petugas sisi udara (airside) untuk saling bersinergritas dalam menjalankan tugas operasional keseharian, pembaharuan sarana penunjang seperti penyimpanan dokumen dan penyediaan alat tulis kantor harus segera dilakukan guna membantu unit apron movement control (AMC) untuk meletakan dokumen record pelanggaran yang terjadi pada sisi udara (airside) serta pemberian reward dan apresiasi yang lebih harus dilakukan untuk meningkatkan motivasi kerja unit apron movement control (AMC).

Sejalan dengan penelitian terdahulu tentang "Analisis Pengawasan PT.Angkasa Pura II (Persero) di Apron Terminal 2F oleh petugas Apron Movement Control (AMC) dalam menurunkan Tingkat Pelanggaran pada Bandar Udara Internasional Soekarno Hatta Tahun 2014 dan 2015" (Pricilia Jeniver, 2016) dapat disimpulkan bahwa keandalan dan kepatuhan perangkat kerja yaitu SDM (sumber daya manusia) pada wilayah apron di Bandar Udara manapun harus selalu mengikuti aturan yang berlaku pada wilayah sisi udara (airside) hal itu guna menjaga keamanan,keselamatan dan kelancaran operasional penerbangan.

\section{Pembahasan Triangulasi}

Setelah peneliti melakukan wawancara terhadap 2 (dua) informan dan 1 (satu) narasumber terpercaya untuk melakukan pengujian keabsahan data menggunakan triangulasi sumber, terkait penelitian "Analisis Pengawasan Apron Oleh Apron Movement Control (AMC) Dalam Meningkatkan Kedisiplinan Di Apron PT Angkasa Pura I (Persero) Bandar Udara Adi SoemarmoSurakarta" maka penulis akanmenjabarkan pembahasan triangulasi tersebut sebagai berikut : Bapak Rewanghadi Widagdo, informan 1 (satu) sebagai apron movement control (AMC) menyatakan bahwa : "hambatan terbesar unit Apron Movement Control (AMC) adalah visualisasi terbatas dalam melakukan pengawasan di bagian sisi udara (airside), kita harus mempuyai kepanjangan tangan dari visualisasi kita yaitu CCTV yang saat ini belum bisa di terapkan dari semua parking stand bandara solo, saat ini visualisasi kita hanya bisa menjangkau 10 parking stand dari 15 parking stand yang ada karena terbatasnya visualisasi kita, lalu kurangnya kepekaan dari teman-teman AMC dalam melihat potensi-potensi yang timbul dari kebiasaan-kebiasaan teman teman ground handling yang dapat menyebabkan potensi pelanggaran atau potensi hazard yang dapat menyebabkan accident incindent di sisi udara tersebut yang di pastikan menyebabkan fungsi pengawasan yang di lakukan AMC belum maksimal dalam meningkatkan kedisipilinan."

Peneliti menyatakan bahwa: "Pada saat ini memang kendala terbesar dalam pengawasan yang dialami oleh apron movement control (AMC) setelah penulis mengobservasi sendiri ke lapangan adalah visualisasi yang terbatas, dimana seperti yang kita ketahui bahwa untuk saat Bandar Udara Adi Soemarmo mempunyai 15 parking stand, sedangkan visualisasi rata-rata personil apron movement control (AMC) hanya sampai pada parking stand nomor 10, pengadaan CCTV (Closed Circuit Television) harus segera di lakukan karena unit apron movement control (AMC) harus memiliki kepanjangan dari visualisasi itu sendiri yaitu CCTV, sejalan dengan itu pelatihan pengawasan harus di lakukan pada personil apron movement control (AMC) secara 
berkesinambungan untuk lebih mempunyai rasa peka atas potensi-potensi pelanggaran yang dapat terjadi di wilayah sisi udara Bandar Udara Adi Soemarmo Surakarta."

Bapak Muhamad Noor, informan 2 (dua) sebagai petugas sisi udara (airside) menyatakan bahwa : "pada dasarnya pengawasan AMC di Bandara Adi Soemarmo ini sudah bagus dan cukup detail seperti peletakan peralatan yang bukan pada tempatnya pun kita di tegur, menurut saya dalam keseharian nya koordinasi antar petugas airside dan AMC sudah berjalan, pada keseharianya apabila petugas airside melakukan pelanggaran ditindak sesuai dengan ketentuan yang berlaku tapi terdapat perbedaan antara petugas AMC, beda petugas beda treatment yang diberikan walaupun tujuannya sama, terkadang petugas sisi udara terpaksa melakukan pelanggaran karena beban kerja berat yang di miliki dan harus segera bekerja sehingga terkadang pelanggaran itu terjadi, contoh seperti dalam melakukan pelayanan sisi udara dan lupa membawa PAS bandara sehingga meminjam PAS bandara orang lain karena apabila harus kembali ke rumah dan mengambil PAS bandara akan menyebabkan take time, pengkajian ulang harus di lakukan oleh AMC ketika menemukan pelanggaran seperti itu melihat runtutan masalah di balik suatu pelanggaran yang terjadi, harapan kedepan komunikasi selalu intens antara AMC dengan petugas sisi udara jangan sampai ada perasaan like and dislike dalam menjalankan operasional keseharian karena terkadang tiap personal juga ada yang menampilkan persaan seperti itu, karena tiap personal kan pribadi nya beda-beda."

Penulis menyatakan bahwa : "Penulis melihat pengawasan yang di lakukan oleh unit apron movement control (AMC) memang sudah berjalan dengan baik walaupun belum sempurna, faktor human tiap personil apron movement control (AMC) yang berbeda-beda dapat saja menghasilkan perbedaan pada saat mentreatment petugas sisi udara (airside) saat melakukan pelanggaran, namun petugas apron movement control (AMC) melakukan penindakan apabila terjadi pelanggaran di sisi udara (airside) tetap berdasarkan SOP (standart operational procedure) yaitu Airside Safety Manual PT Angkasa Pura I (Persero), Apron Movement Control (AMC) Manual PT Angkasa Pura I, dan Pedoman Pengoprasioan Kendaraan Di Wilayah Airside Bandar Udara PT Angkasa Pura I (Persero) lalu faktor beban kerja yang berat pada petugas sisi udara bukan merupakan sebuah alasan mengapa sebuah pelanggaran dapat terjadi pengkajian beban kerja petugas sisi udara harus di selesaikan oleh pihak manajemen perusahaan penyedia jasa pelayanan sisi udara tersebut, kedepan komunikasi antar petugas sisi udara (airside) dengan petugas apron movement control (AMC) harus lebih ditingkatkan lagi untuk menumbahkan sinegritas antar stakeholders terkait."

Bapak Kasnoto, narasumber sebagai Airport Duty Manager (ADM) PT Angkasa Pura I (Persero), menyatakan bahwa : "pertama-tama di jelaskan tugas utama ADM adalah sebagai koordinator pengawas dalam operasional keseharian, tugas dan tanggung jawab ADM di bawah naungan general manager dan senior manager, menanggapi persoalan pengawasan apron oleh AMC dalam meningkatkan kedisiplinan di apron, pertama-tama koordinasi antara ADM selama ini dengan AMC sudah cukup baik dalam hal berkaitan dengan pengawasan di sisi udara walaupun belum sempurna, lalu pengawasan yang dilakukan oleh AMC dalam meningkatkan kedisiplinan sebenarnya belum bisa di katakan baik seutuhnya ditambah jumlah penerbangan yang masih bisa di handle serta masih dalam batas wajar, tapi kedepan apabila bandara adi soemarmo terdapat peningkatan penerbangan rasa nya petugas AMC harus mendapatkan pelatihan lebih baik lagi dan lebih ketat lagi dalam melakukan fungsi pengawasan daripada sekarang, nah terkait pelanggaran yang sudah terjadi di sisi udara sebenarnya selain pengawasan yang belum sempurna oleh AMC pihak airlines pun atau groundhandling sudah mempunyai SOP nya sendiri dalam menjalankan tugas dan ini harus bersinergritas antara AMC dengan pihak stakeholders petugas sisi udara, peningkatan sinergritas rasanya harus di lakukan dengan melakukan briefing bulanan antara AMC dengan stakeholders terkait yaitu petugas sisi udara perlu juga dihadirkan pihak safety dalam briefing bulanan itu untuk mengedukasi keselamatan dan keamanan penerbangan guna meminimalisir potensi terjadinya pelanggaran yang selama ini belum di laksanakan, saat ini pengembangan sistem juga sedang di laksanakan dengan penyempuranaan bagian airport operation control center (AOCC) ini juga merupakan langkah pemantauan operasional sisi udara."

Peneliti menyatakan bahwa : Peran sinergritas antara stakeholders harus lebih di tingkatkan kedepannya, koordinasi bulanan harus di rencanakan antar stakeholders terkait bagian operasional penerbangan yang selama ini tidak pernah diadakan, selain hal tersebut pelatihan berkesinambungan pada petugas apron movement control (AMC) harus di lakukan mengingat tingkat penerbangan yang dapat saja meningkat di Bandar Udara Adi Soemarmo Surakarta lebih lagi dengan penambahan jumlah parking stand yang kini mempunyai 15 parking stand dan Bandar Udara Adi Soemarmo Surakarta yang kini juga melayani penerbangan khusus haji dan umroh, dalam menekan tingkat pelanggaran yang terjadi pengembangan unit airport operation control center (AOCC) harus di lakukan dengan cepat guna mempermudah pemantauan dan koordinasi antar stakeholders juga pengadaan visualisasi CCTV (Closed Circuit Television) harus segera di lakukan 
menyesuaikan keadaan sekarang yang kini mempunyai 15 parking stand di apron Bandar Udara Adi Soemarmo Surakarta.

\section{KESIMPLAN DAN SARAN}

Peneliti menyimpulkan bahwa : 1) Jumlah pemakaian tertinggi aviobridge/garbarata tahun 2019 sebesar 970 kali di bulan Januari dan terendah sebesar 767 kali di bulan Mei, total pemakaian aviobridge/garbarata 10109 pemakaian, rata-rata pemakaian 842,42 perbulan, dengan rata-rata kegunaaan kenaikan dan penurunan sebesar -166 setiap bulan, dapat diartikan terdapat penurunan pemakaian sebesar -1,64\% perbulan, 2) Jumlah pelanggaran yang dilakukan pada sisi udara (airside) tahun 2019 yang paling sering dilakukan adalah berkendara melebihi $25 \mathrm{~km} /$ jam pada service road berjumlah 11 orang, memasuki wilayah sisi udara (airside) tidak sesuai dengan PAS bandara 10 orang, tidak mengenakan alat pelindung diri (APD) 7 orang, tidak memiliki tanda izin mengemudi (TIM) 6 orang dan yang paling sedikit di langgar adalah tidak mempuyai PAS bandara dan mengenakan PAS orang lain sebanyak 5 Orang, 3) Peran kerja unit Apron Movement Control (AMC) dalam menaikan tingkat kedisiplinan di apron, dari 26 variabel terdapat 4 variabel dengan nilai terendah yaitu : a) variabel Manpower tipe faktor penyebab bagian komunikasi, b) Machnines tipe faktor penyebab bagian sarana penunjang, c) Motivation tipe faktor penyebab bagian reward.

\section{Daftar Pustaka}

A.Morissan. (2012). Metode Penelitian Survei. Jakarta: Kencana.

Creswell, J. W. (2016). Pendekatan Metode Kualitatif, Kuantitatif, dan Campuran. Yogyakarta: Pustaka Pelajar.

Eko, W. S. (2015). Manajemen Pengembangan Sumber Daya Manusia. Yogyakarta: PUSTAKA PELAJAR.

Gaspersz, V. (2012). All In One Practical Management Excellence. Jakarta: Vinchristo Publication.

Hasibuan, M. (2016). Manajemen Sumber Daya Manusia. Edisi Revisi. Jakarta: PT Bumi Aksara.

Heizer, J., \& Rander, B. (2015). Operations Management (Manajemen Operasi), ed.11, Penerjemah: Dwi Anoegrah wati S dan Indra Almahdy . Jakarta: Salemba Empat.

Heizer, J., \& Render, B. (2014). Manajemen Operasi, Manajemen Keberlangsungan Rantai Pasokan. Jakarta: Salemba Empat.

M.Manullang. (2018). Dasar- dasar Manajemen. Jakarta: Ghalia Indonesia.

Muchdarsyah, S. (2014). Produktivitas: Apa dan Bagaimana. Jakarta: Bumi Aksara.

P.Tampubolon, M. (2014). Manajemen Operasi \& Rantai Pemasok (Operation and Supply-chain Management).(Edisi Pertma). Jakarta: Mitra Wacana Media.

Pamungkas, R., SP, A. R., \& Ramadhan, B. (2019). Kajian Pengawasan Personil Apron Movement Control (AMC) Terhadap Ground Support Equipment (GSE) Di Apron Terminal 3 Bandar Udara Internasional Soekarno-Hatta Jakarta. Prosiding Seminar Nasioanal Inovasi Teknologi Penerbangan (SNTP), 8.

Sinambela, L. P. (2017). Manajemen Sumber Daya Manusia. Jakarta: PT Bumi Aksara.

Sugiyono. (2013). Metode Penelitian PendidikanPendekatan Kuantitatif, Kualitatif, dan R\&D. Bandung: Alfabeta.

Sugiyono. (2017). Metode Penelitian Kuantitatif, Kualitatif, dan R\&D. . Bandung: Alfabeta.

Sutrisno, E. (2016). Manajemen Sumber Daya Manusia. Jakarta: Media Group.. 